\title{
From Human Trafficking to Modern Slavery: The Development of Anti-Trafficking Policy in the UK
}

\author{
Rose Broad $^{1} \cdot$ Nick Turnbull $^{2}$
}

Published online: 22 March 2018

(C) The Author(s) 2018

\begin{abstract}
The UK Modern Slavery Act 2015 is the first national legislation to use the term 'modern slavery' and to explicitly target 'slavery' as opposed to 'human trafficking', 'forced labour', or other terms. This article explains the development of UK modern slavery policy, which did not arise as a rational response to a defined problem, but has gradually emerged from the policy process as a moderately structured problem. Problem structuring took place in two phases. The first phase was marked by a series of problematisations and policy responses, with disjunctions between the constructed policy problem and the social problem. Elite problematisations excluded alternatives, although the final shape of policy remained open. Policy built up incrementally, running ahead of research so that the policy frame was limited to sexual exploitation while marginalising labour exploitation concerns. In the second phase, unresolved problems of legislation were questioned under the influence of a new moralistic policy frame, an international discourse on slavery, supported by elite political actors. Campaign groups and licit industry also became more influential, increasing the policy scope to take in more types of exploitation. This generated a second round of legislative problematisation, ultimately embedded in the Modern Slavery Act 2015. The two-phase process and prevailing top-down policy direction worked against human rights discourses and victim protection. Modern slavery remains a moderately structured problem, with more work necessary to address unintended consequences and implementation difficulties, including enhancing multi-agency working.
\end{abstract}

Keywords Criminal policy $\cdot$ Modern slavery $\cdot$ Human trafficking $\cdot$ Policy work $\cdot$ Policy questioning $\cdot$ Interpretive policy analysis

Rose Broad

rosemary.broad@manchester.ac.uk

Nick Turnbull

nick.turnbull@manchester.ac.uk

1 Centre for Criminology and Criminal Justice, School of Law, University of Manchester, Oxford Rd, Manchester M13 9PL, UK

2 School of Social Sciences, University of Manchester, Oxford Rd, Manchester M13 9PL, UK 
The UK Modern Slavery Act 2015 is unique in being the first national legislation to use the term 'modern slavery' and to explicitly target 'slavery' as opposed to 'human trafficking', 'forced labour' or other terms. ${ }^{1}$ This idea is spreading, with countries worldwide - e.g. France, Australia $^{2}$ and the United States - moving to legislate specifically against modern slavery. These activities have been reconceptualised in recent times and are now firmly cemented as (inter)national policy priorities. However, prior to the late 1990s, attention to such activities was not a common feature of policy or academic discourse. Many reasons have been identified for the political, legal and social focus on trafficking as a crime including increasing links to prostitution (Weitzer 2007), increased focus on organised crime, in particular the operation of major crime entrepreneurs in red-light districts (van Duyne and Vander Beken 2008) and the collapse of communist regimes in Eastern and Central Europe leading to economic stagnation and unemployment (Mai 2010). Explaining the development of legislation and policy in the UK case is significant for understanding criminal policy in this field. Very little scholarship has charted the process regarding modern slavery policy in the UK; Craig (2017) a notable exception, effectively identifying the work remaining in order to achieve the goal of 'abolishing slavery'. Our analysis makes an original contribution to understanding modern slavery policy, firstly by charting the policy process, and secondly by applying an analytical lens from public policy studies to reveal the forces acting upon and through the policy process in this case. By focusing on the policy process in its full scope, from its discourse of problematisation to implementation practices, this analysis adds a significant new perspective and empirical detail to modern slavery scholarship.

While policy activity surrounding slavery and trafficking has increased, it would be an error to imagine policymaking has comprised a straightforward, problem-solving response to a defined, empirical problem. The extent and measurement of trafficking and modern slavery has been seriously questioned on definitional and empirical grounds (Savona and Stefanizzi 2007; Weitzer 2007, 2015). The problem of modern slavery is far from self-evident, having been constructed by various means, including policy actions and influential discourses. Therefore, in explaining UK modern slavery policy, this paper rejects accounts based on a linear, rational, problem-solving model of policymaking and instead utilises a framework from public policy studies, incorporating an interpretative and practice-based conception of policymaking (Hoppe 2010; Turnbull 2006, 2013). This analytical framework is able to show how a series of incremental responses and new political discourses led to the recent Act, and how the problem of modern slavery emerged from policy practice, as much as policy responded to the problem. This paper proceeds by first outlining the benefits of this analytical approach. We then consider the UK case in two phases of policymaking: Phase One, comprising the emergence of human trafficking on the political and legislative agenda; and Phase Two, the enactment and implementation of the Modern Slavery Act 2015. It is argued that policy remains problematic and continues to marginalise vulnerable groups.

\footnotetext{
${ }^{1}$ We acknowledge that terminology surrounding this policy is very problematic. Modern slavery covers a much broader range of activity than human trafficking: a person subject to modern slavery may not have been 'trafficked'. It is partly the aim of this article to discuss the elision of human trafficking and modern slavery. The term human trafficking has been chosen in the title because, although it has been replaced in much policy discourse in the UK, it remains the more commonly used term.

${ }^{2}$ See Australian Government consultation on the need for a Modern Slavery Act based on the UK model: http://www.huffingtonpost.com/entry/modern-slavery-an-issue-for-australia_us_5888398ee4b0a53ed60c6a7d
} 


\section{Problem-Structuring Versus Problem-Solving}

The passing of legislation is often assumed to reflect a rational government response to solve a defined problem. In the case of modern slavery, it might be inferred that the existence of legislation confirms the reality of slavery as a discrete problem. However, viewing modern slavery policy through a policymaking lens offers a more nuanced trajectory. Over many decades, public policy scholars have criticised the assumption that policymaking is problemsolving as a founding myth (Rein and White 1977). Instead, policymaking practice is: characterised by partial solutions, incremental advances, and political compromise (Lindblom 1965); pre-structured by the 'appreciative systems' or interpretive frames of policy actors (Yanow 1996; Vickers 1965); and concerns problem-setting and problem-structuring, more than goal-directed problem-solving (Hoppe 2010; Turnbull 2006). Problems are structured over time such that they emerge from policy workers' practice-based reasoning and actions without requiring a defined problem nor goal in mind (Colebatch et al. 2010). Individual policy actors may certainly respond strategically to empirical and political problems, but the policymaking process is so diverse ('governance' by networks rather than 'government'; Rhodes 1997) — in which governments can only make policy appear to be an authoritative choice ex-post facto - and the problems themselves so much in question, that the problem-solving presupposition is entirely insufficient to explain the policy process. Such an explanation must be sought by examining several factors: how problems are defined, the contextual shaping of problem-setting, and the incremental accretion of actions over time by policy workers. Policymaking is less linear than spiralling in trajectory, because actors continually reformulate problems in order to adapt to change and legitimise their actions (see Turnbull 2013).

Nevertheless, even in a world of governance, government retains considerable power to frame policy problems in such a way as to direct policy (Bell and Hindmoor 2009), and to steer networks through 'metagovernance' (Sørensen and Torfing 2009). Governments have disproportionate power to set agendas, which constrains the scope of activities by interest groups outside the state (Kingdon 1984: 81). Following such policy problem definition, change tends to occur only incrementally, even following major shortcomings. Furthermore, the process of using information in official decision-making projects a "symbolic value of expressing the perceived rational foundations of choices" (Radaelli 1995: 162). That is, the official problematisation of an issue as a policy problem serves to normalise it. Most problematisations attract critics, but the weight of government power in defining problems exerts the strongest force.

Such top-down problem definition is commonly found in crime policy. Crime-related policy (particularly in cross-border cases) is often developed by (inter)national bureaucratic and legal institutions, guided by overarching definitions. 'Bureaucratic entrepreneurs' (Levi 2009) have the power to institutionalise and reinforce policy in (inter)national political contexts within coherent 'epistemic communities' (Haas 1992). This is particularly applicable to the UK, "where policy formation is the purview of a restricted governmental elite" (Schmidt and Radaelli 2004: 198). The elite centralisation of power is a core aspect of the British Political Tradition (Richards and Smith 2015). In this environment, policymaking features strong, identifiable discursive themes within problem-setting and responses. Further, certain aspects of the problem, which may be found in NGO anti-trafficking campaigns or research are excluded. Through the processes of policy framing and incrementalism, policy silences can be perpetuated, particularly for problems of a global scope. The framing activities of elite actors 
produce 'hegemonic discourses' (Wesselink et al. 2013) that exclude alternative problematisations and governance practices. Dorn (2010) explained the potentially dangerous consequences of (inter)national convergence of policy standards, which create common blind spots. The 'blind spots' of hegemonic discourse in anti-trafficking strategy include types of trafficking that fall outside the dominant frame or unintended policy consequences, for example marginalising migrant sex workers (Agustin 2006).

We draw on insights from the 'policy work' (Colebatch et al. 2010; Hoppe 2010) and interpretive questioning perspectives (Turnbull 2006, 2013) to posit a framework which identifies how UK modern slavery policy emerged over time via a series of incremental actions and elite framing practices. Using Hoppe's (2010: 245) idea of problem-setting as a process which gradually develops definitions of problems along a continuum, we characterise modern slavery as a moderately structured problem. Problem structuring does not involve application of a one-time solution, but regularises policy processes as a partial answer. Unstructured problems acquire a provisional structure via a repressing answer in regard to a prior situation, becoming moderately structured. However, such problem-structuring responses also have an opening-up property, insofar as either the factual uncertainties or normative ambivalences around the issue require further research or political negotiation (Hoppe 2010: 74, 79-85). By contrast, a structured problem is one in which "members of [the]...policy community are closer to agreement on norms and values at stake, and closer to certainty on required and available knowledge" (Hoppe 2010: 245; Mills 1970). Modern slavery is moderately structured because it involved (some) normative agreement between stakeholders but also exhibited a degree of uncertainty around knowledge, the policy debate around effectiveness and risk distribution. In the case of UK modern slavery policy, problem structuring took place in two phases. The first phase marked the initial (re)recognition of the problem, relating to a time frame spanning from the mid-1990s to around 2013. The second phase relates to the development of 'modern slavery' legislation beginning towards the end of the first phase. Both have been marked by a series of problematisations and policy responses, highlighting disjunctions between the constructed policy problem and empirical realities, and showing how elite problematisations excluded alternatives, even if the final shape of policy remained somewhat open. Thus, the limited knowledge of human trafficking during the early development of policy (largely relating to sexual exploitation of women and girls) provided the context against which this phase of policymaking was problematised. Subsequent responses were built upon previous partial solutions, such that anti-trafficking policy emerged from a series of incremental actions, running ahead of research. Thus, the implicit question treated, i.e. the policy frame, was limited to sexual exploitation. Then the experiences of campaign groups, followed by involvement of key organisations representing licit industry, along with identification of alternative types of exploitation, altered the questions being asked and generated a second phase of legislative problematisation, ultimately embedded in the Modern Slavery Act 2015. However, the problems had been reframed under the unifying banner of 'slavery', with a new moral dimension and amplified symbolic power.

\section{Phase One: The UN Protocol and Implementation of UK Trafficking Legislation}

Although the United Nations Convention for the Suppression of the Traffic in Persons and the Exploitation of the Prostitution of Others was adopted in 1949, human trafficking did not 
become a focus of interest until the mid-1990s. ${ }^{3}$ The renewed focus on the problem has been attributed to several factors including the increased international interest in organised crime, particularly following organised-crime related murders of two Italian judges in 1992. This was coupled with building anxiety regarding migration and the perceived expansion of international illegal markets following the collapse of former communist regimes (Mai 2010). Despite increased international policy focus, this was not paralleled with research that would have informed a more robust evidence base. Since its inception, problems have been identified with the shape of human trafficking policy and the nature of the response (Broad 2013; DanailovaTrainor and Laczko 2010; Salt 2000). The shape of trafficking policy was thus questioned from the beginning, particularly by groups outside the dominant construction, who interpreted it within the context of their professional, political and institutional experiences.

The UK government was thus politically motivated to deal with an emerging problem, such that the first response was a top-down political action, primarily to legitimise government authority in response to international pressure to act, rather than a problem-based inquirydirected activity (Turnbull 2013). The UK response was thereby situated within and prompted by global awareness-raising about human trafficking that structured nation states' policymaking. In 2000, the Protocol to Prevent, Suppress and Punish Trafficking in Persons Especially Women and Children supplementing United Nations Convention against Transnational Organised Crime (hereinafter referred to as The Protocol), provided the foundation for global anti-trafficking policy. That umbrella of the Convention against Transnational Organised Crime firmly shaped the framework for national responses. Doezema $(2005,2010)$ effectively analysed the processes through which The Protocol was drafted and argued that sex worker narratives remained absent, despite raising concerns about the potential harmful outcomes for these workers, and the inheritance of historical 'white slavery' myths into the policy frame.

Prior to this phase of policymaking, UK responses to activities of this nature had to be managed by legislation not entirely suited to the problem. This included the Sexual Offences Act 1956 (SOA): 'causing the prostitution of women' (s.22) or other offences such as assault or false imprisonment. The maximum sentence under the SOA 1956 was two years, which was considered insufficient given the perceived gravity of the activities. It was therefore superseded by the SOA 2003, which contained offences related to trafficking for sexual exploitation. ${ }^{4}$ Parallel to this, the Immigration Act 1971 legislated for the facilitation of illegal entry into the UK, which had been used to deal with circumstances involving illegal movement where evidence was insufficient to pursue other offences. The Asylum and Immigration Act 2004 contained a provision regarding trafficking for forced labour but was limited in scope. However, political pressure also arose from below and impacted upon legislative direction. Following campaigning by organisations such as Anti-Slavery International and Liberty, a new offence of slavery, servitude and forced labour was introduced in the Coroners and Justice Act 2009 (s.71). Thus, the policy problematisation clearly divided trafficking into two distinct problems; sexual exploitation and labour exploitation, with the focus firmly on the former, via the global frame. This then led to a separation of responses to these policy problems, with the remit for sexual exploitation falling to law enforcement units responsible for other sexual

\footnotetext{
${ }^{3}$ For a comprehensive review of UN policy, see Farrior 1997.

${ }^{4}$ Following the provisions contained in the Nationality, Immigration and Asylum Act 2002, which was regarded as an interim measure to deal with trafficking activity pending the development of the SOA 2003 (Skrivankova 2007).
} 
offences and the latter being dealt with, if at all, through border control or piecemeal responses by officers experienced in dealing with sexual exploitation. ${ }^{5}$

The problem itself was thus structured by a combination of existing legislation and political pressures from national and supra-national actors. Further structuring effects can be found from both sources, including the activities of civil society organisations. The National Referral Mechanism (NRM) was a policy initiative introduced during Phase One, answering questions posed primarily by NGOs in order to provide more support to trafficked victims. It was initiated in the UK as a result of the ratification of the Council of Europe Convention on Action against Trafficking in Human Beings (April 2009) illustrating the growing focus on victim protection. Through the NRM, designated 'competent authorities' refer cases for assessment to decide whether there is sufficient evidence to prove victimisation. Systems of victim protection in the UK were developed while balancing the targets of the then United Kingdom Border Agency (UKBA) regarding the removal of undocumented migrants leading to criticism of their level of commitment to victim care (Balch and Geddes 2011). It has increasingly been recognised that non-statutory organisations have an important role in identifying and referring potential victims to official authorities and understanding the way in which victims present their experiences. Significant problems have been identified by NGO professionals working with victims, of the poor response experienced by victims and particularly the lack of support following the 45 days provided in the legislation ${ }^{6}$ (Human Trafficking Foundation 2016; ATMG 2013). Although the government NRM pilot and review (Home Office 2017a) identified many of these problems, no substantive changes have been made; also identified by the National Audit Office review of modern slavery (Home Office 2017b). The reliance of the NRM on a "coherent, consistent and undelayed victim disclosure" has been criticised given many victims' mistrust of authority (Anti-Slavery Commissioner 2017). This policy response has lacked the nuance to deal effectively with victims despite the increasing prominence of victim protection in problem-setting and the role of non-official actors in understanding the needs of victims.

Although employment-driven migration has long been part of the policy context for trafficking, the issues of labour exploitation were essentially unexplored during the first phase. The impacts of Phase One legislation were largely felt by migrant workers through mechanisms to target migration by alternative means. These earlier policy responses were dominated by a migration-crime-security frame (Goodey 2008), rather than through an understanding of employment and exploitation associated with migration. The development of policy in this area took place within the context of an immigration and crime crisis in 2006 following the release of over a thousand migrant prisoners without consideration of deportation (Balch and Geddes 2011). This was coupled with a focus on the exploitative conditions in which many migrants worked, brought to the fore by the Morecambe Bay tragedy of 2004 which led to the establishment of the then Gangmasters Licencing Authority $\left(\mathrm{GLA}^{7}\right)$. This policy development, although welcomed in terms of improving the level of market regulation, was criticised as only occurring as a result of tragic circumstances (Skrivankova 2007). International actors in this field did not act quickly enough to influence the policy frame: "The International Labour Organisation (ILO) maintained a decidedly low profile during the [policy] negotiations

\footnotetext{
${ }^{5}$ For example, see Broad 2013.

${ }^{6}$ At the time of writing, a private members bill put forward by Lord McColl to extend support available to victims is under consideration.

${ }^{7}$ Now the Gangmasters Labour Abuse Authority following changes to the remit of the organisation, see http://www.gla.gov.uk/who-we-are/our-aims-and-objectives/the-gangmasters-and-labour-abuse-authority/
} 
[and]...further deprived the negotiations of crucial expertise on forced labour and child labour issues" (Chuang 2013: 616). The ILO (2005) subsequently produced a report that incorporated issues of forced labour into the problematisation of trafficking. Whilst this was crucial in terms of the introduction of forced labour into the frame, it occurred only after The Protocol and the first phase of the UK legislation, leaving the policy response in need of change. Similarly, early opportunities for communication between the GLA and those involved in targeting trafficking were missed (Skrivankova 2007) and these issues remained outwith the policy frame.

Since the outset, the posing of policy questions has had an enduring impact. The problematisation of trafficking as the sexual exploitation of young women and girls saw an underutilisation of legislation targeting labour exploitation (Skrivankova 2007). The Home Office (2008) reported a total of 84 convictions for trafficking offences during 20042008 with only six convictions for trafficking for labour exploitation; two of which attracted custodial sentences. The presence of forced and exploitative labour in the human trafficking frame began to increase in official accounts during this phase. The UK Action Plan on Tackling Human Trafficking (Home Office 2007) identified objectives to increase the knowledge base, enforcement activity, prosecutions for and resources allocated to trafficking for labour exploitation. The 2011 'Human Trafficking: The Government's Strategy' stated that "trafficking for labour exploitation could become more prevalent than other forms" (Home Office 2011: 5) and identified the importance of engagement with labour inspectorates. Despite shifting recognition of the problem and increased attention on forced labour in the late $2010 \mathrm{~s}$, limitations persisted because "trafficking has often been interpreted in a narrow way in the UK" (Dwyer et al. 2011: 32). In the context of the continued gaps in research on trafficking for the purposes of labour exploitation, policy responses often continued to focus on trafficking for sexual exploitation.

The 2011 Government Strategy set out four key principles: improved victim identification and care; reducing the threat (alluding to organised threat assessment); more effective action at the border; and improved coordination. This built on 'A Strong New Force at the Border' (Home Office 2008) and the 'UK Action Plans on Tackling Human Trafficking' (Home Office 2007), which located human trafficking in the frame of migration and security. Lee (2011) argued that this approach lacked a robust evidence base and instead dealt with the so-called 'risks' of illegal migration, leading to the criminalisation of migrants. Much of the earlier legislative and counter-trafficking provisions were competing with immigration-focused legislation, balancing the needs of trafficked victims with immigration restrictions. The fourth key principle (more effective coordination) represented an important addition to the policy frame leading to the development of multi-agency approaches to human trafficking and widened the remit for tackling human trafficking from primarily law enforcement to a model which included a wide range of actors, including corporations (discussed further below).

The moderately structured problem that emerged created a very clear and specific foundation for human trafficking policy. However, this was only one possible formulation of the problem, influenced by the UN Protocol, existing legislation, and the limited role of activist groups (Doezema 2005, 2010). Without working towards any agreed-upon goal, this problematisation created the problem itself by posing an implicit question: 'how to protect innocent, naïve, young women from evil, organised (and largely migrant) criminal men?' The resultant problem thereby focused efforts on the 'rescue' of young women, primarily sex workers (Agustin 2008). Consequently, in the early stages of policy action, responses often took the form of brothel raids. Media narratives characterised victims of trafficking as (often attractive) vulnerable young women (Berman 2003). Thus, the direction taken both at policy 
and operational level in answering the policy problem explicated the same elements of the problem and repressed others, contributing to the stability of anti-trafficking policy and practice as a moderately structured problem.

\section{Phase Two: The Emergence of 'Modern Slavery'}

The second phase of policymaking built upon the first, with the focus of this reproblematisation on exclusions of the existing legislation, arising from political mobilisation by activist groups and a new discourse introduced by powerful domestic political actors. The term 'human trafficking' has largely been replaced with 'modern slavery' in activist campaigns, legislation and political discourse, following strong advocacy by former Home Secretary and now Prime Minister Theresa May, to reframe and structure the problem as a general problem of slavery. This policy change has occurred despite problems and resistance to this move particularly regarding the widening remit of 'modern slavery' (see Chuang 2013; Balch and Geddes 2011). This shift requires explanation. There were certainly important domestic actors involved, but international influences were also present in the form of antislavery activism through 'new abolitionist' discourse (O'Connell Davidson 2015) promoted at the domestic level. Also crucial was the continuing UK context of heightened public concern about immigration, linked with anti-EU sentiment and the perceived negative effects of globalisation on many citizens, challenging the major political parties (Clarke et al. 2016). The problem of trafficking was expanded to include a wider range of activities (Chuang 2013) under the new policy frame of 'modern slavery'. A Home Office review of modern slavery related activity identified 17 types, ranging from benefit-related crime to the movement of people to trade drugs (Home Office 2017c). This framing has established a more structured problematisation, evincing a strong moral component. The new discourse of slavery, promoted by the government and key think tank The Centre for Social Justice, then supported by activist groups, helped to solidify the discourse and thereby act intersubjectively to 'reduce complexity' (Jessop 2010; see Mayblin 2016) and provide more structure to the problem, at least in terms of symbolic meaning, even if many problematic elements remain, as discussed below.

Reports from the Anti-Trafficking Monitoring Group (ATMG 2013) and the Centre for Social Justice (CSJ 2013) identified several problems with the existing legislation, particularly the need to develop more coordinated multi-agency approaches and to increase victim protection. They recommended in response (amongst other things) a single modern slavery Act. The 'collateral damage' of early trafficking policy has been well documented, including the criminalisation of migrant sex workers, increasingly restrictive border controls and increased surveillance of the sex industry (see Agustin 2006; Kempadoo 2015; Sanders 2007; ) in addition to disparities in the prosecution processes between the legislation aimed at sexual exploitation and that aimed at labour exploitation (Home Office 2011). A growing evidence base identifying forced labour in a diverse range of markets (Skrivankova 2014) contributed to a new approach, "albeit in a piecemeal and incremental fashion" (Balch 2015: 88) as new questions were introduced into the policy framework, changing the understanding of the problem. As a result, policy consultations were initiated throughout 2013 and the draft Modern Slavery Bill was presented to Parliament in December (Home Office 2013). In this way, a new process of problematisation not only dealt with limitations of the existing trafficking legislation, but afforded an opportunity to reframe several problems under one banner: 'modern slavery'. 
This questioning sought to deal with exclusions arising from weak implementation practices. Building on recommendations from the 2013 reports, a government review highlighted the efficacy of multi-agency work in anti-trafficking strategy including co-location and the inclusion of non-statutory agencies in the planning and execution of enforcement operations (Home Office 2014). There is emerging evidence that a multi-agency organised crime focused law enforcement strategy is effective (Kirby and Nailer 2013). However, these multi-agency approaches are still in early stages of development (Harvey et al. 2015) and further research is required to identify the ways in which organisations can coordinate their actions and how this can broaden and inform policy response, particularly in relation to how institutions can contribute responses that challenge the dominant narrative.

The opportunities presented by multi-agency working models were partially mediated by top-down policymaking. The Protocol and dominant narrative had already defined the problem as one of (transnational) organised crime and therefore required a law enforcement response. This frame was adopted over a possible alternative, grounded in human rights, despite concerns regarding deterioration of victims' rights without a significant human rights focus (Jordan 2002; Villacampa and Torres 2017). Under initial legislation, and perhaps due to the marginalisation of a human rights orientation, many states provided inadequate support for victims of trafficking (Chuang 2013), posing a policy problem that has resulted in the more detailed provisions for victims in the Act as discussed above. However, providing support for a group of people who are often at the periphery of employment and society has proven difficult, particularly in the context of restrictive migration policy and increasing hostility towards migrant workers. Thus, the law enforcement frame tended to counter the stated intention of improved victim protection. At a more general level, the law enforcement response differs from the human rights view in viewing victims as entirely lacking in agency, as having been exploited against their own free will, whereas a human rights frame would give rights to workers by conceding the possibility of choice in their actions.

The influence of the Catholic Church via the CSJ modern slavery report ( 2013) — an influential think tank founded by key Conservative Party figure Iain Duncan Smith — was vital in framing the new abolitionist character of the policy. The involvement of the Catholic Church in the propagation of modern slavery discourse is extensive and has been building for some time (see Catholic News Agency 2008). This has been institutionalised in the form of the Santa Marta Group, initiated in Britain and now internationalised, which organises conferences and conducts advocacy. This Vatican-endorsed organisation is an important Transnational Moral Entrepreneur (TME) (Nadelmann 1990) promoting the abolition of new forms of exploitation under the banner of slavery. Along with important liberal TMEs, such as Bales (1999, 2005), contemporary anti-slavery activists have propagated a new discourse and morality in support of a global prohibition regime (Nadelmann 1990) enacted in criminal law within individual nation-states. The actions of religious and liberal forces evoke a resonance with historical anti-slavery campaigns of previous centuries, however the full nature of these campaigns has yet to be researched. ${ }^{8}$ In the UK, the law enforcement response bolstered the underlying strong moral claims of the legislation by instituting a strongly protectionist mode of state action. This policy response contributed to further problem structuring, allowing other problems to be subsumed and treated similarly. The British Political Tradition of elite, top-down government and Theresa May's more interventionist mode of policymaking - part of a new 'post-liberalism' in social policy found on both the

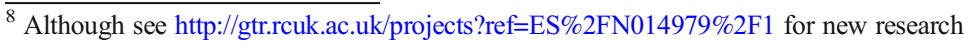


right and left of British politics (Sage 2012) — were also important forces behind the legislative provisions and marginalisation of alternative voices.

The Act defines modern slavery as including human trafficking, slavery, forced labour and domestic servitude. The term therefore incorporates not only human trafficking but a range of other behaviours previously defined as forced labour, prompting a criticism of 'exploitation creep' (Chuang 2013: 611). This includes the operation of two key problem structuring processes: 1) all forced labour becomes defined as trafficking, regardless of the absence of movement, and 2) all trafficking is labelled as slavery. These definitions were introduced despite existing, extensive international regulation and policy knowledge. Forced labour had been addressed through a complex, broad and inconsistent range of international frameworks (Balch 2015). Although forced labour was incorporated into anti-trafficking policy prior to Phase Two, as noted above, questions around the efficacy of law enforcement approaches to it remained largely absent, repressed in favour of responses addressing sexual exploitation. Balch (2015) has criticised the inclusion of forced labour within this policy frame, arguing that it produces confusion for regulators and neglects to recognise the need for a tailored response.

The discursive change from 'trafficking' to 'slavery' created a significant change in the perception of the problem and the policy response. Media attention to exploitative practices such as those in the garment industry and the Qatar football World Cup preparations have expanded the problem from one primarily of sexual exploitation, happening to other people, elsewhere, to one with UK links, impacting on products consumed by the public (Craig 2014). Of course, 'slavery' is not new in the trafficking frame. Continuities and discontinuities have been identified by those considering parallels between historic slavery and modern slavery with a movement away from total and permanent ownership towards understanding slavery along a continuum of experiences (Skrivankova 2010) including, for example, forced labour or debt bondage, although the term remains problematic in alluding to complete control (Bales 2005; O'Connell Davidson 2015; Weitzer 2015). The term 'slavery' is heavily weighted and emotive, serving political functions (Balch 2015) and, similarly to the term 'trafficking', lacks conceptual clarity and consistency of meaning (Chuang 2013). The lack of clarity further emphasises the emotional impact of the term 'slavery', which draws public attention to the issues but also uses the 'moral' as a legitimate basis for policy interventions.

The use of the term 'slavery' can shift campaign foundations from a robust evidence base to being driven by moral impetus. The 'moral crusades' associated with trafficking have parallels with the purity movements of the late 1800 s/early 1900 s, with responses ostensibly framed around protection of women and girls, which frequently resulted in more punitive measures (Spencer and Broad 2011; Weitzer 2007; Gorham 1978). Kempadoo (2015: 18) has argued that, from an international perspective, these campaigns are taken on by "a neoliberal white chivalrous crusade across the world, born of a moral sense of goodness that shores up the power and subjectivity of the North, with the 'developing' Global South and East as the dumping grounds for helping imperatives involving rescue and charity", which are largely ineffective. Anti-slavery operations in late 2016 and early 2017 have raised concerns regarding the conflation of modern slavery and migration, illustrating parallels with operations conducted under Phase One of the legislation leading to negative outcomes for migrant workers. For example, Operation Magnify targeted UK nail bars, resulting in the arrest of approximately 100 migrant workers (Guardian 2016). This mirrors the outcomes of earlier approaches, such as Operations Pentameter I and II (Guardian 2009) which resulted in arrest and 
deportation of migrant sex workers. Continuing this theme, potential victims of modern slavery have been identified as being detained in immigration detention centres, unable to disclose their experiences or receive support (HMICFRS 2017). Thus, despite superficial changes to policy focus, strategy has continued to marginalise migrant workers and exclude them from structures of support.

The Act has included provisions to widening responsibility for labour exploitation to include corporations; provisions also featured in the developing policies of other countries, for example, New Zealand. The Transparency in Supply Chain provisions (s.54) represent a new structuring of the problem. However, this is not the first attempt in the UK to legislate for this type of corporate responsibility. The UK Company Supply Chains (Eradication of Slavery) bill was brought before Parliament in 2012 but was not passed. Criticisms of the debate and decision were framed around the incongruence between this policy and policies promoting corporate self-regulation (Phillips 2015) and in the wider context of holding corporations responsible for criminal activity (Lord and Broad 2018). At the time of writing, some organisations have published statements required under s.54 with varying recognition of modern slavery as an issue in their supply chains as well as a varying commitment to tackling it. ${ }^{9}$ The obligations do not carry penalties for non-compliance, instead relying on moral and consumer drivers for corporate change. Despite this, these provisions have been viewed as robust in theory but failing to acknowledge the wider context of market pressures and structures that can facilitate recourse to trafficking and/or exploitative labour (New 2015; Phillips 2015). Radical critics have argued that, in this construction of the problem, the pathologies of global capitalism are ignored as the key context for exploitation, with antislavery activism implicitly upholding neoliberalism by distancing 'us' from 'them' through an othering by racialised stereotypes (Kempadoo 2015; Agustin 2008). Alternatively, one could argue against this, insofar as anti-slavery policy represents a liberal activism in continuity with the past, and at the same time a post-liberal reaction against the excesses of globalisation by reasserting the moral authority of the nation-state over the exploitative effects of global trade, including of labourers and sex workers. Whatever the case, the difficulty of recognising exploitation falling outside the dominant slavery narrative was identified by campaign groups and contributed to the legislative overhaul (ATMG 2013), as well as being recognised in the response to the Modern Slavery Bill (Public Bill Committee 2015). However, despite broadening the types of exploitation and the type of legal 'persons' that might be responsible, the experiences of those outside the dominant narrative remain on the periphery.

The Act thus includes the potential to shift policy answers to the problem from one which is entirely criminal justice based to one that is shared between criminal justice and corporate responsibility. Throughout the development of the Bill and the Act, Theresa May has pledged to work with business to combat the problem (HM Government 2015). However, there continue to be tensions between the policy questions and policy answers regarding the extent to which it "is more suggestive of a 're-branding' of anti-trafficking policy" (Balch 2015: 94), coupled with concern that the corporate responses will be a tick box exercise (Phillips 2015). Despite the ostensibly positive motivation to widen the scope of this legislation to protect larger groups of workers, policy developments have been criticised as a way of dealing with issues of migrant workers' rights and creating spurious links between anti-trafficking legislation and frameworks of labour policy (Balch 2015; Chuang 2013; Kempadoo 2015). Posing

\footnotetext{
${ }^{9}$ The Business and Human Rights Resource Centre maintains a public record of these statements. Available at: https://business-humanrights.org/en/uk-modern-slavery-act-registry
} 
questions in the context of policies aimed at labour policy and the rights of migrant workers creates responses that strengthen labour rights protection and interrogate supply chains, shifting some responsibility from the hands of organised criminals to those of corporations through (currently unenforceable) due diligence and compliance. Without more robust tools to ensure compliance with s.54, associated action may not become embedded in the policy response. Furthermore, broader questions regarding the legal and socio-political context that facilitates conditions conducive to slavery (of any type) have yet to be asked or answered within this policy framework.

\section{Conclusions}

The development of modern slavery policy in the UK cannot be explained as a rational response to an identified social problem. Nor is policy development a linear process of increasing problem-solving capacity. It is, rather, a product of a policy process characterised by a series of questioning processes and incremental decisions, responses to implementation problems, and affected by influential framing discourses on trafficking and slavery. The process proceeded in two main phases. At each stage, the problem was given more structure, yet also opened up new problems to be tackled. Modern slavery itself, via the Modern Slavery Act 2015, emerged from this process, as the Act played a crucial role in constructing slavery as a problem, as much as it aimed to solve it. The legislation constitutes only a partial solution to the various problems brought under the unified slavery banner. Hence, modern slavery remains a moderately structured problem, with more work necessary to address the unintended consequences of the policy and implementation difficulties, such as enhancing multi-agency working, which has been highlighted as crucial in relation to information sharing and the coordination of compliance and prevention action. Limitations lie in the fact that policymaking was characterised by top-down decision-making, which excluded key actors and prevented it being informed by a robust evidence base. This top-down process, along with the strong moral component of global anti-slavery discourse, encouraged a law enforcement response, excluding engagement with the marginalised populations the law was designed to assist. The strong moral discourse of slavery has important symbolic consequences for problem structuring and implementation. More research is needed into the political dimensions of this policy frame, with regard to the influence of TMEs in propagating anti-slavery discourse, the strategies and beliefs of individual government ministers, and patterns of new abolitionist and human rights discourses in international politics. For now, it is evident that both anti-trafficking and anti-slavery discourses played a role in structuring UK public policy and in serving the political legitimation of several governments, with anti-immigration and anti-European Union public sentiment as important contextual factors.

Policy action under the Act is developing under these circumstances. Political support for anti-trafficking measures continues, with Theresa May signalling her commitment by allocating $£ 33$ million to such measures. Trafficking policy discourses have previously been criticised for being used to justify restrictive migration policies. On the basis of anti-slavery operations, it appears that some of these outcomes are continuing under the Act. Despite criticisms, the immigration frame has persisted in anti-trafficking and forced labour policy discourse. Trafficking should not be viewed 
as a problem resulting from migration but instead must be understood as one of a range of issues related to the complexities of migration. These complexities will no doubt become more intricate as Brexit conditions are negotiated, ${ }^{10}$ potentially placing larger groups of people into vulnerable employment and migratory areas.

Open Access This article is distributed under the terms of the Creative Commons Attribution 4.0 International License (http://creativecommons.org/licenses/by/4.0/), which permits unrestricted use, distribution, and reproduction in any medium, provided you give appropriate credit to the original author(s) and the source, provide a link to the Creative Commons license, and indicate if changes were made.

\section{References}

Agustin, L. (2006). The disappearing of a migration category: Migrants who sell sex. Journal of Ethnic and Migration Studies, 32(1), 29-47.

Agustin, L. (2008). Sex at the margins: Migration, labour markets and the rescue industry. London: Zed.

Anti-Slavery Commissioner (2017). Identifying, referring and supporting victims of modern slavery in the UK's national referral mechanism. Open letter to Sarah Newton MP. Available at: http://www. antislaverycommissioner.co.uk/media/1114/letter-to-sarah-newton-mp-on-the-national-referral-mechanism. pdf. Accessed 12/04/17.

ATMG. (2013). In the dock: Examining the UK's criminal justice response to trafficking. London: AntiTrafficking Monitoring Group.

ATMG (2017). Brexit and the UK's fight against modern slavery. Anti-Trafficking Monitoring Group: London. Available at https://www.antislavery.org/wp-content/uploads/2017/07/ATMG-Brexit-paper.pdf. Accessed 23 $/ 01 / 18$.

Balch, A. (2015). Understanding and evaluating UK efforts to tackle forced labour. In G. Craig, L. Waite, H. Lewis, \& K. Skrivankova (Eds.), Vulnerability, exploitation and migrants: Insecure work in a globalised economy (pp. 86-98). Basingstoke: Palgrave Macmillan.

Balch, A., \& Geddes, A. (2011). Opportunity from crisis? Organisational responses to human trafficking in the UK. The British Journal of Politics and International Relations, 13(1), 26-41.

Bales, K. (1999). New slavery in the global economy. Berkeley: University of California Press.

Bales, K. (2005). Understanding global slavery: A reader. Oakland: University of California Press.

Bell, S., \& Hindmoor, A. (2009). Rethinking governance: The centrality of the state in modern society. Cambridge: Cambridge University Press.

Berman, J. (2003). (un)popular strangers and crises (un)bounded: Discourses of sex trafficking, the European political community and the panicked state of the modern state. European Journal of International Relations, 9(1), 37-86.

Broad, R. (2013). Stuck in traffic. Doctoral thesis available https://www.escholar.manchester.ac.uk/uk-ac-manscw:221262. Accessed 16/08/17.

Catholic News Agency (2008). Human trafficking is modern slavery, says Vatican official. Vatican City, 15 February. Available at: http://www.catholicnewsagency.com/news/human_trafficking_is_modern_slavery_ says_vatican_official/. Accessed 21 August 2017.

Centre for Social Justice. (2013). It happens here: Equipping the United Kingdom to fight modern slavery. London: Centre for Social Justice.

Chuang, J. (2013). Exploitation creep and the unmaking of human trafficking law. American Journal of International Law, 108(4), 609-649.

Clarke, H., Whiteley, P., Borges, W., Sanders, D., \& Stewart, M. (2016). Modelling the dynamics of support for a right-wing populist party: The case of UKIP. Journal of Elections, Public Opinion and Parties, 26(2), $135-154$.

Colebatch, H. K., Hoppe, R., \& Nordegraaf, M. (Eds.). (2010). Working for policy. Amsterdam: Amsterdam University Press.

Craig, G. (2014). The global markets in modern day slavery. Criminal Justice Matters, 97(1), 6-7.

Craig, G. (2017). The UK's modern slavery legislation: An early assessment of progress. Social Inclusion, 5(2), $16-27$.

Danailova-Trainor, G., \& Laczko, F. (2010). Trafficking in persons and development: Towards greater policy coherence. International Migration, 48(4), 38-83.

${ }^{10}$ For a review of the potential impact of Brexit on modern slavery strategy, see ATMG 2017. 
Doezema, J. (2005). Now you see her, now you don't: Sex workers at the un trafficking protocol negotiation. Social and Legal Studies, 14(1), 61-89.

Doezema, J. (2010). Sex slaves and discourse matters. London: Zed.

Dorn, N. (2010). The governance of securities: Ponzi finance, regulatory control, credit crunch. British Journal of Criminology, 50(1), 23-45.

Dwyer, P., Lewis, H., Scullion, L., \& Waite, L. (2011). Forced labour and UK immigration policy: Status matters? York: Joseph Rowntree Foundation.

Farrior, S. (1997). The international law on trafficking in women and children for prostitution: Making it live up to its potential. Harvard Human Rights Journal., 10, 213-256.

Goodey, J. (2008). Human trafficking: Sketchy data and policy responses. Criminology and Criminal Justice, $8(4), 21-442$.

Gorham, D. (1978). The 'maiden tribute of modern Babylon' re-examined: Child prostitution and the idea of children in late-Victorian England. Victorian Studies, 21(3), 353-379.

Guardian (2009). Inquiry fails to find a single trafficker who forced anybody into prostitution Nick Davies. Available at: https://www.theguardian.com/uk/2009/oct/20/government-trafficking-enquiry-fails. Accessed 10/01/17

Guardian (2016). Home Office targets nail bars over illegal immigration Rowena Mason. Available at: https://www.theguardian.com/uk-news/2016/dec/28/home-office-targets-nail-bars-over-illegal-immigration. Accessed 10/01/17.

Haas, P. (1992). Epistemic communities and international policy coordination. International Organisation, 46(1), $1-35$.

Harvey, J. H., Hornsby, R. A., \& Sattar, Z. (2015). Disjointed service: An English case study of multi-agency provision in tackling child trafficking. British Journal of Criminology, 55(3), 494-513.

HM Government (2015). Transparency in supply chains: a practical guide. London: HM Government.

HMICFRS (2017). Stolen freedom: the policing response to modern slavery and human trafficking. HMICFRS: London. Available at https:/www.justiceinspectorates.gov.uk/hmicfrs/wp-content/uploads/stolen-freedomthe-policing-response-to-modern-slavery-and-human-trafficking.pdf. Accessed 23/01/18.

Home Office. (2007). UK action plan on tackling human trafficking. London: Home Office.

Home Office. (2008). A strong new force at the border. London: Home Office.

Home Office. (2011). Human trafficking: The Government's strategy. London: HM Government.

Home Office. (2013). Draft Modern Slavery Bill. London: The Stationery Office.

Home Office. (2014). Multi-agency working and information sharing project. London: Home Office.

Home Office (2017a). An evaluation of the national referral mechanism pilot. Research Report 94. Home Office: London. Available at https:/www.gov.uk/government/uploads/system/uploads/attachment_data/file/653703 /evaluation-national-referral-mechanism-pilot-horr94.pdf. Accessed 23/01/18.

Home Office (2017b) Reducing modern slavery. National Audit Office report HC630. Home Office: London. Available at https://www.nao.org.uk/wp-content/uploads/2017/12/Reducing-Modern-Slavery.pdf. Accessed 23/01/18.

Home Office (2017c). A typology of modern slavery offences in the UK. Home Office: London. Available at https:/www.gov.uk/government/uploads/system/uploads/attachment_data/file/652652/typology-modernslavery-offences-horr93.pdf. Accessed 23/01/18.

Hoppe, R. (2010). The governance of problems. Bristol: Polity Press.

Human Trafficking Foundation (2016). Day 46. Available at http://www.humantraffickingfoundation. org/sites/default/files/Human\%20Trafficking\%20Foundation\%20Report\%202016\%20Day\%2046.PDF. Accessed 23/01/18.

ILO. (2005). A global alliance against forced labour. Geneva: International Labour Office.

Jessop, B. (2010). Cultural political economy and critical policy studies. Critical Policy Studies, 3(3-4), 336356.

Jordan, A. (2002). Human rights or wrongs: The struggle for a rights-based response to trafficking in human beings. Gender and Development, 10(1), 28-37.

Kempadoo, K. (2015). The modern-day white (wo)man's burden: Trends in anti-trafficking and anti-slavery campaigns. Journal of Human Trafficking, 1(1), 8-20.

Kingdon, J. (1984). Agendas, alternatives and public policies. New York: Harper Collins.

Kirby, S., \& Nailer, L. (2013). Reducing the offending of a Uk organised crime group using an opportunity reducing framework: A three year case study. Trends in Organised Crime, 16, 397-412.

Lee, M. (2011). Trafficking and global crime control. London: Sage.

Levi, M. (2009). Suite revenge: The shaping of folk devils and moral panics about white collar crime. British Journal of Criminology, 49(1), 48-67.

Lindblom, C. E. (1965). The intelligence of democracy: Decision making through mutual adjustment. New York: Free Press. 
Lord, N., \& Broad, R. (2018). Corporate failures to prevent serious and organised crimes: Foregrounding the 'Organisational' component. European Review of Organised Crime, 4(3), $27-52$.

Mai, N. (2010). The psycho-social trajectories of Albanian and Romanian 'traffickers'. Institute for the Study of European Transformations Working Paper No. 17.

Mayblin, L. (2016). Complexity reduction and policy consensus: Asylum seekers, the right to work, and the 'pull factor' thesis in the UK context. British Journal of Politics and International Relations, 18(4), 812-828.

Mills, C.W. (1970[1959]). The sociological imagination. Harmondsworth: Penguin.

Nadelmann, E. (1990). Global prohibition regimes: The evolution of norms in international society. International Organisation, 44(4), 479-526.

New, S. (2015). Modern slavery and the supply chain: The limits of corporate social responsibility? Supply Chain Management: An International Journal, 20(6), 697-707.

O'Connell Davidson, J. (2015). Modern slavery: The margins of freedom. Basingstoke: Palgrave Macmillan.

Phillips, N. (2015). Private governance and the problem of trafficking and slavery in global supply chains. Vulnerability, Exploitation and Migrants. Basingstoke: Palgrave Macmillan. pp. 15-27.

Public Bill Committee (2015). Modern slavery bill: written evidence PBC (Bill 008) 2014-2015. Available at: http://www.publications.parliament.uk/pa/cm201415/cmpublic/modernslavery/memo/modernslavery.pdf. Accessed 10/01/17.

Radaelli, C. (1995). The role of knowledge in the policy process. Journal of European Public Policy, 2(2), $159-183$.

Rein, M., \& White, S. (1977). Policy research: Belief and doubt. Policy Analysis, 3, 239-271.

Rhodes, R. A. W. (1997). Understanding governance: Policy networks, governance, reflexivity and accountability. Buckingham: Open University Press.

Richards, D., \& Smith, M. (2015). In Defence of British politics against the British political tradition. Political Quarterly, 86(1), 41-51.

Sage, D. (2012). A challenge to liberalism? The communitarianism of the big society and blue labour. Critical Social Policy, 32(3), 365-382.

Salt, J. (2000). Trafficking and smuggling: A European perspective. International Migration, 1, 31-56.

Sanders, T. (2007). No room for a regulated market? The implications of the co-ordinated prostitution strategy for the indoor sex industries. Safer Communities, 6(1), 34 44.

Savona, E. and Stefanizzi, S. (Eds.). (2007). Measuring human trafficking: Complexities and pitfalls. New York: Springer.

Schmidt, V., \& Radaelli, C. (2004). Policy change and discourse in Europe: Conceptual and methodological issues. West European Politics, 7(2), 183-210.

Skrivankova, K. (2007). Collateral damage: The impact of anti-trafficking measures on human rights around the world. Global Alliance Against Traffic in Women. Available at: http://www.antislavery.org/wpcontent/uploads/2017/01/collateraldamage_2007.pdf. Accessed 17/02/17.

Skrivankova, K. (2010). Between decent work and forced labour: Examining the continuum of exploitation. York: Joseph Rowntree Foundation.

Skrivankova, K. (2014). Forced labour in the United Kingdom. York: Joseph Rowntree Foundation.

Sørensen, E., \& Torfing, J. (2009). Making governance networks effective and democratic through metagovernance. Public Administration, 87(2), 234-258.

Spencer, J., \& Broad, R. (2011). The groundhog day of human trafficking for sexual exploitation: New directions in criminological understanding. European Journal on Criminal Policy and Research, 18(3), 269-281.

Turnbull, N. (2006). How should we theorise public policy? Problem solving and problematicity. Policy and Society, 25(2), 3-22.

Turnbull, N. (2013). The questioning theory of policy practice: Outline of an integrated analytical framework. Critical Policy Studies, 7(2), 115-131.

van Duyne, P. C., \& Vander Beken, T. (2008). The incantations of the EU organised crime policy making. Crime, Law and Social Change, 51(2), 261-281.

Vickers, G. (1965). The art of judgement: A study of policy making. London: Chapman \& Hall.

Villacampa, C. and Torres, N. (2017). Human trafficking for criminal exploitation: the failure to identify victims. European Journal on Criminal Policy and Research, 1-16.

Weitzer, R. (2007). The social construction of sex trafficking: Ideology and the institutionalisation of a moral crusade. Politics and Society, 35(3), 447-475.

Weitzer, R. (2015). Human trafficking and contemporary slavery. Annual Review of Sociology, 41, $223-242$.

Wesselink, A., Buchanan, K. S., Georgiadou, Y., \& Turnhout, E. (2013). Technical knowledge, discursive spaces and politics at the science-policy interface. Environmental Science \& Policy, 30, 1-9.

Yanow, D. (1996). How does a policy mean? Interpreting policy and organizational actions. Washington: Georgetown University Press. 